\title{
Motivations for participation in physical activity across the lifespan
}

\author{
James Gavin · Matthew Keough • Michael Abravanel · Tatiana Moudrakovski \\ Madeleine Mcbrearty
}

\begin{abstract}
This investigation explored motivations for engaging in physical activity and how they varied across the lifespan. A total of 1,885 individuals completed a comprehensive questionnaire concerning personal style, activity interests, motives for exercising, and biosocial information as part of an initiative to improve physical activity advisement and programming. The first part of the research called for an exploratory factor analysis (EFA) of a 20-item measure of both intrinsic and extrinsic motivations related to participation in exercise, while the second was based in an analysis of differences on the EFA factor scores across five age groups: teens, 20s, 30s, 40s, and 50 s+. EFA results suggested a four-factor (oblique rotation) solution that appeared to provide an adequate and generalizable map of intrinsic and extrinsic motivations for exercise. The factors were labeled as follows: mental toughness, toned and fit, fun and friends, and stress reduction. Not surprisingly, mean scores on toned and fit were the highest of the four factor means across all age groups. Univariate ANOVAs of age group differences were statistically significant for each of the four factors; moreover, all four factors showed statistically significant linear trends. Two factors, toned and fit and stress reduction, revealed higher motivation scores with increasing age, while the remaining two, mental toughness and fun and friends, exhibited declining scores with increasing age. These findings taken in the context of previous research on age-related motivational differences offered insights into current challenges for enhancing exercise participation, particularly for older individuals.
\end{abstract}

Keywords: lifespan, age differences, physical activity, exercise motivation, exploratory factor analysis

\section{Motivations for participation in physical activity across the lifespan}

It is widely acknowledged that participating in regular physical activity (PA) is highly beneficial for both physical health and psychological wellbeing (Centers for Disease Control and Prevention [CDC], 2011a; Ford et al., 2012; U.S. Department of Health and Human Services, 2008). Yet, sedentary lifestyles are increasingly the norm among North Americans (Brownson, Boehmer, \& Luke, 2005). Only 20.6\% of the adult American population meets basic PA guidelines for aerobic and muscle-strengthening physical activity (Centers for Disease Control and Prevention [CDC], 2011b), while Canada shows a similarly low rate of PA participation of only $15 \%$ who satisfied the recommended PA guidelines of 150 minutes of moderate-to-vigorous physical activity per week (Colley et al., 2011). Low levels of PA have been associated with a number of life-threatening health problems, including coronary heart disease, adult onset diabetes, hypertension, and depression (CDC, 2011a; Rangul, Bauman, Lingaas Holmen, \& Midthjell, 2012). Research further indicates that PA participation levels decrease with age (Baker, 
Fraser-Thomas, Dionigi, \& Horton, 2010; Human Resources and Skills Development Canada, 2013); this trend portends poorly for a world where lengthening lifespans are likely to be associated with dramatic increases in health care costs and related social issues (Breyer, CostaFont, \& Felder, 2010; Janssen, 2012). Given the personal and societal costs of inactivity, the need to integrate regular PA participation into modern lifestyles seems paramount (Breyer et al., 2010; Trujillo, Brougham, \& Walsh, 2004).

Understanding motivations to pursue active lifestyles can be key to decreasing the proportion of sedentary individuals in society (Hagger, 2012; Trujillo et al., 2004). Indeed research on exercise motivation is extensive, with much of it grounded in Deci and Ryan's selfdetermination theory (SDT; see Deci \& Ryan, 1985; Hagger \& Chatzisarantis, 2007; Teixeira, Carraça, Markland, Silva, \& Ryan, 2012; Vallerand, Donahue, \& Lafrenière, 2012). Deci and Ryan's (1985) theory proposes that motivation to exercise varies along a continuum from intrinsic to extrinsic. Being intrinsically motivated means carrying out an activity for the inherent satisfaction and enjoyment that it provides (Deci, 1975), while extrinsic motivation refers to engaging in an activity for its instrumental purpose or to gain something outside of the activity itself (Deci \& Ryan, 1985). As Vallerand (2008) observes, a fundamental distinction between intrinsic and extrinsic motivation is a lack of liking for the activity itself.

Extrinsic motivators, such as wanting to increase physical attractiveness, seem most effective in initiating exercise initiatives (Dishman, 1987; Lim, Ting, Loh, Loo, \& Shaikh, 2013; McAuley, Wraith, \& Duncan, 1991; Morgan, Shephard, \& Finucane, 1984), while it is thought that long-term maintenance of exercise behaviors depends more on intrinsic motivation (Gallagher \& Updegraff, 2011; McAuley et al., 1991; Wankel, 1985, 1988, 1993). Nonetheless, a common perspective is that intrinsic motivation alone cannot sustain a physically active lifestyle (Edmunds, Ntoumanis, \& Duda, 2006; Mullan \& Markland, 1997). Ryan, Williams, Patrick, and Deci (2009) assert, "most people maintain their exercise activities not because the activities are inherently interesting or enjoyable to them but because they have something to gain in it" (p.111). These authors go on to argue that extrinsic motivations are essential in the realm of physical activity, especially when individuals do not experience adequate challenge and autonomy in their programs (Deci \& Ryan, 1985; Ryan, Koestner \& Deci, 1991).

Our research was concerned with how intrinsic and extrinsic motivations related to PA might vary across the lifespan (Brunet \& Sabiston, 2011; Trujillo et al., 2004). We anticipated that findings of this nature would be invaluable for guiding activity-promoting interventions (Conn, Hafdahl \& Mehr, 2011; Frederick-Recascino, 2002; Hobbs et al., 2013; Schieffer \& Thomas, 2012).

\subsection{Investigations involving multiple age groups}

In a broad perspective, motivation to engage in physical activity seems to decrease with age (Biddle, 2007; Brunet \& Sabiston, 2011; Koslow, 1988; Prochaska, Leventhal, Leventhal, \& Keller, 1985; Ransford \& Pailisi, 1996; Seippel, 2006; Trujillo et al., 2004). However, not all motives show declines. In Ashford, Biddle and Goudas's (1993) study of 15 key motives for sports participation, older adults (45+) were found to be more motivated than young (16-24) and mature (25-44) adults by factors such as mental health and socio-psychological wellbeing. Similarly, Seippel (2006) notes in his study of 1,400 Norwegian participants aged 13 and older that the only dimension where a higher score was found for older compared to younger study participants was one reflecting involvement in PA as a mental recreation; otherwise, younger individuals consistently reported more reasons for exercising.

Another study (Trujillo et al., 2004) involving 461 adult participants aged 18 to 86 described an inverse linear trend between age and the importance of physical appearance consequences of 
PA. Moreover, Koslow's (1988) study of 300 individuals grouped into three categories (18-30, 3140 , and 41-50) indicated that the 31-40 and 41-50 groups placed greater emphasis on health benefits of exercise than did the 18-30 group.

\subsection{Studies of single age groups}

Studies of exercise motivation within particular age cohorts also have bearing on our research though it was difficult to assess whether the central motives identified in these investigations were more or less salient than at other periods of life. For instance, a prevalent motivator for participation among adolescents (age 11-19) was described as enjoyment of what they were doing (Biddle, Wang, Chatzisarantis \& Spray, 2003); other studies identified health benefits as relevant sources of motivation for this age cohort (Gavin, Mcbrearty \& Harvey, 2013). In a study of middle-aged adults (mean age 40), health, fitness, and physical appearance were found to be high PA motivators (Ingledew \& Markland, 2008). Among older adults (62-91) perceived functional independence, competition, self-care, and social involvement were identified as contributors to exercise motivation (Miller \& Iris, 2002).

\subsection{Framework for investigation}

Our investigation represents one of a limited number of studies focusing on age-related motivational differences across the lifespan (Brunet \& Sabiston, 2011; Martín-Albo, Núñez, Domínguez, León, \& Tomás, 2012; Netz \& Raviv, 2004; Seippel, 2006). Uniquely, our study compared five age groupings ranging from teens to 50 and over. As an initial step in our research, we examined the factor structure of a 20-item exercise motivation measure both to understand how various intrinsic and extrinsic motives were aligned and also to facilitate a concise understanding of age group differences. We envisioned that information from our research would contribute to theoretical understanding, while also having pragmatic value through informing initiatives promoting active lifestyles for different age groups (Edmunds et al., 2006; Mullan \& Markland, 1997).

\section{Methods}

\subsection{Measurements}

A comprehensive questionnaire regarding personal style, activity interests, motives for exercising, and biosocial information was created for a series of investigations related to individuals' engagement in sports and physical activity (Gavin, 2004; Gavin, Mcbrearty \& Harvey, 2010). Pertinent to this study, 20 potential sources of motivation were listed in one section of the questionnaire. These included such motivators as becoming fit, reducing stress, having fun, and making friends. Many of these motives have been represented in other studies of physical activity motivation (Ashford et al., 1993; Gallagher \& Updegraff, 2011; Lim et al., 2013). The questionnaire required individuals to indicate on a 3-point scale whether each item was a reason why they exercised; the response choices were "yes", "?", and "no." Analysis of the 20-item questionnaire was integral to this investigation, and is described in the results section.

Respondents' age was requested in a section of the questionnaire pertaining to biosocial information. Given the large number of participants in this investigation, age groupings were created from participants' reported actual ages; more information about this is presented in the description of participants below. 


\subsection{Data collection}

Data were collected in eight branches of the Montreal, Quebec YMCA, which was piloting a project to better advise members regarding activity choices and their requirements (Gavin, 2006). In approving this project, the Montreal YMCA reviewed all processes of the questionnaire and related activities for ethical compliance. The comprehensive questionnaire referred to above was presented through single usage touchscreen computers located in the lobbies and training areas of the branches; these computers were dedicated to the project and served no other purpose than that of presenting the questionnaire for members to complete. Participants were invited through signage and other promotional information to access the questionnaires on the touchscreen computers; questionnaire completion took approximately 25 minutes. Once an individual advanced beyond the opening screen of the program, a consent page was presented wherein individuals learned that the questionnaire was completely anonymous and that a record of their responses would be kept on the computer for future analysis of aggregated data. No names or membership information were required to log in to the computer; moreover, participants could skip the biosocial questions reflecting some identifying information such as age if they wished. Participants had the option of discontinuing the questionnaire at any point in the process of its completion, and thereby having all their responses deleted from the hard drive. After finishing, participants were offered a summary report based on their responses. They were further invited to have this report reviewed in a confidential session with a YMCA fitness specialist who would help them better appreciate how to initiate or maintain rewarding patterns of physical exercise.

Periodically, designated YMCA staff members copied the data files from the computers' hard drives and sent them to the researchers. Data on the hard drives were then erased.

\subsection{Participants}

The number of questionnaire responses obtained from the touchscreen computers was 2,041. Whenever individuals chose to terminate questionnaire completion prior to the last question, all their responses were deleted. Thus, it was impossible for us to determine how many individuals may have commenced but not completed the questionnaire. However, it was possible for individuals to skip questions in some sections of the questionnaire. For this reason, the number of usable questionnaires for this research was reduced from 2,041to 1,885; 156 participants had incomplete data sets pertaining to either age or the motivation questions.

Participants' self-assessed activity levels ranged from inactive to highly active, though the sample as a whole appeared to be proportionately more active than the general population: $27.8 \%$ reported exercising at most 1-2 times per month, another $24.3 \%$ described exercising 1-2 times per week, and the remaining $47.9 \%$ indicated exercising 3 or more times weekly. This variation from expected population percentages (Centers for Disease Control and Prevention, 2011b; Colley et al., 2011) could be anticipated given the setting for the research. Findings, therefore, need to be understood to be descriptive of a more active segment of the population.

For the purpose of the analyses reported in the results section, participants were grouped into five decade-defined categories; these categories and the related numbers of participants were as follows: Teens ( $n=180), 20-29(n=846), 30-39(n=431), 40-49(n=256), 50$ and over $(n=172)$. The decision to group participants by age decades was based, in part, on age and stage theories that describe life progression according to periods of life (cf. Erikson, 1980, 1982; Kegan, 1982, 1994; Levinson, 1978, 1996). We thought this would be more meaningful than using the unique age distribution of this sample to determine subgroups. There were marginally significant age group differences in positive attitudes toward physical activity $\left(F_{4,1880}=2.38, p=.05, \eta^{2}=.005\right)$ and in self-reported participation rates $\left(F_{4,1880}=2.38, p=.05, \eta^{2}=.005\right)$; however, the linear trend 
across groups was non-statistically significant $\left(F_{1,1880}=.14, p=.71\right)$ for attitude toward physical activity and marginally significant for participation $\left(F_{1,1880}=3.75, p=.05\right)$ with the older groups reporting modestly more weekly activity rates.

\subsection{Data screening and analytic plan}

Analyses for the current study proceeded in two stages: First, an exploratory factor analysis (EFA) was conducted in Mplus version 2.12 (Muthen \& Muthen, 2002). The EFA was conducted on the 20-item motivations scale. According to Kline (2013), a minimum of 10 cases per observed variable in a factor analysis is needed to have adequate power. The total sample size in the present study was $N=1885$, thereby providing us with ample power to conduct the EFA. Given that the factors were derived from item level data that used a three-point response scale, a Weighted Least Squares (WLS) estimation method was used. Items that use response scales that have fewer than five options should be treated as categorical data (Kline, 1998). An EFA with such items is considered problematic because the estimated correlations between categorical observed variables are typically lower than the correlations for underlying continuous latent variables (O'Connor, Colder, \& Hawk, 2004). The WLS estimation method adjusts the covariance matrix as if the variables were continuous. Second, composite subscale means were created for the factors based on the pattern of primary factor loadings. These subscales were used in a series of univariate ANOVAs to investigate age differences in motivations for exercise.

Before conducting the analyses, the data were screened according to the recommendations of Wilkinson (1999) and Kline (2009). There was no systematic loss of data based on this screening. All continuous variables were normally distributed and scores greater than 3 SDs were replaced with the highest acceptable value within the specified range (Kline, 2009). The data did not violate the homogeneity of variance assumption in ANOVA, as the ratio between the largest and smallest group variances was less than 3.0 (Kline, 2009).

\section{Results}

\subsection{Exploratory factor analysis}

The EFA was conducted using the full 20-item measure. The extraction method was principle axis factoring with an oblique rotation method. An oblique rotation was preferred in this case because this method allows the factors to correlate (Meyers, Gamst, \& Guarino, 2013). Given that this is one of a limited number of studies (e.g., Ashford et al., 1993; Kasser \& Ryan, 1996) to investigate the factor structure of exercise-related motivations, we decided against specifying the number of factors a priori. We determined the number of retained factors based on Kaiser's (1960) Eigenvalue-greater-than-one rule. In addition, items with primary factor loadings of less than .32 (Tabachnick \& Fidell, 2013) were trimmed, and the EFA was re-run.

The eigenvalue-greater-than-one suggested a four-factor solution. When the factor loadings were inspected, we found that 2-items had small correlations with their respective underlying factor (i.e., $r<.32$ ); therefore, these items were trimmed from the analysis. The final retained EFA is presented in Table 1 (below). 
Table 1. Final EFA solution for the motivations scale

\begin{tabular}{lcccc}
\hline Item & F1 & F2 & F3 & F4 \\
\hline 1. Develop mental toughness & .68 & .10 & .43 & .26 \\
2. Become more assertive & .60 & .11 & .36 & .25 \\
3. Build self-esteem & .61 & .16 & .21 & .35 \\
4. Reduce negative habits & .48 & .21 & .07 & .30 \\
5. Create opportunities for personal achievement & .63 & .15 & .34 & .26 \\
6. Develop greater focus \& concentration & .64 & .18 & .31 & .39 \\
7. Learn new skills for life & .66 & .11 & .43 & .31 \\
8. Prevent future health problems & .11 & .40 & -.01 & .31 \\
9. Shape my body \& increase physical attractiveness & .09 & .55 & .08 & .25 \\
10. Improve endurance & .17 & .52 & .20 & .34 \\
11. Be physically fit & .17 & .66 & .06 & .28 \\
12. Be with friends or make new friends & .30 & .04 & .47 & .17 \\
13. Have fun & .20 & .32 & .46 & .30 \\
14. Enjoy the challenge and excitement of competition & .26 & .04 & .57 & .02 \\
15. Live more adventurously & .49 & .04 & .56 & .18 \\
16. Reduce stress \& release tension & .26 & .41 & .15 & .68 \\
17. Deal with moods and anxiety & .37 & .18 & .18 & .56 \\
18. Increase feelings of relaxation & .36 & .27 & .16 & .54 \\
\hline Eigenvalues & 4.5 & 2.0 & 1.3 & 1.1 \\
\hline
\end{tabular}

Note: F1 = mental toughness; F2 = toned and fit; F3 = fun and friends; F4 = stress reduction.

The primary factor loadings are in bold font.

Factor 1 contained items that reflected mental toughness motives and Factor 2 represented motives centered on staying toned and fit. Factor 3 captured motives of having fun and being with friends, while Factor 4 reflected motivations to exercise for stress reduction. The internal consistencies for the factors were as follows: Factor 1: mental toughness $(\alpha=.81)$, Factor 2: toned and fit $(\alpha=.70)$, Factor 3: fun and friends $(\alpha=.70)$, Factor 4: stress reduction $(\alpha=.71)$. Given the adequate to good internal consistencies of these factors, composite subscale means were created based on the primary factor loadings of the items. The bivariate correlations and descriptive statistics for these subscales are presented in Table 2.

Table 2. Correlations and descriptive statistics for motivations subscales

\begin{tabular}{lcccc}
\hline & 1 & 2 & 3 & 4 \\
\hline Mental toughness & - & $.21^{* *}$ & $.45^{* *}$ & $.44^{* *}$ \\
Toned and fit & & - & $.10^{* *}$ & $.33^{* *}$ \\
Fun and friends & & & - & $.24^{* *}$ \\
Stress reduction & & & & - \\
\hline$M$ & 2.36 & 2.88 & 2.17 & 2.60 \\
$S D$ & .62 & .27 & .61 & .58 \\
** $p<.001$ & & & &
\end{tabular}

\subsection{Univariate ANOVAs}

Having found few studies of exercise-related motivations across age groups (Ashford et al., 1993; Koslow, 1988; Seippel, 2006; Trujillo et al., 2004), we believed there to be insufficient evidence to 
articulate a priori hypotheses about expected group differences. Thus, we conducted a series of univariate ANOVAs, followed by polynomial trend analyses (i.e., linear, quadratic, cubic) to examine the nature of age group differences on motivations. The main purpose of these trend analyses was exploratory. Based on the five age groups of interest (teens, 20s, 30s, 40s, and 50s+), we explored group differences on the four motivations subscales indicated by the EFA results.

The results of the ANOVAs and linear trend analyses are summarized in Table 3.

Table 3. Summary of ANOVA analyses for group differences in motivations

\begin{tabular}{|c|c|c|c|c|c|}
\hline Source & SS & df & MS & $\mathbf{F}$ & $\mathrm{p}$ \\
\hline \multicolumn{6}{|c|}{ Factor 1: Mental toughness } \\
\hline Age Group & 16.15 & 4 & 4.04 & 10.73 & $<.001$ \\
\hline Linear & 14.33 & 1 & 14.33 & 38.11 & $<.001$ \\
\hline Quadratic & 1.36 & 1 & 1.36 & 3.61 & .06 \\
\hline Cubic & .23 & 1 & .23 & .61 & .43 \\
\hline Error & 707.32 & 1880 & .38 & & \\
\hline Total & 723.47 & 1884 & & & \\
\hline \multicolumn{6}{|c|}{ Factor 2: Toned and fit } \\
\hline Age Group & 2.41 & 4 & .60 & 8.70 & $<.001$ \\
\hline Linear & 1.64 & 1 & 1.64 & 23.79 & $<.001$ \\
\hline Quadratic & .70 & 1 & .70 & 10.04 & $<.01$ \\
\hline Cubic & .07 & 1 & .07 & .98 & .32 \\
\hline Error & 130.29 & 1880 & .07 & & \\
\hline Total & 132.70 & 1884 & & & \\
\hline \multicolumn{6}{|c|}{ Factor 3: Fun and friends } \\
\hline Age Group & 9.74 & 4 & 2.43 & 6.67 & $<.001$ \\
\hline Linear & 8.86 & 1 & 8.86 & 24.31 & $<.001$ \\
\hline Quadratic & .05 & 1 & .05 & .15 & .69 \\
\hline Cubic & .51 & 1 & .50 & 1.41 & .23 \\
\hline Error & 685.27 & 1880 & .37 & & \\
\hline Total & 695.00 & 1884 & & & \\
\hline \multicolumn{6}{|c|}{ Factor 4: Stress reduction } \\
\hline Age Group & 8.60 & 4 & 2.15 & 6.56 & $<.001$ \\
\hline Linear & 1.76 & 1 & 1.76 & 5.37 & $<.001$ \\
\hline Quadratic & 3.82 & 1 & 3.82 & 11.68 & $<.001$ \\
\hline Cubic & 2.95 & 1 & 2.95 & 9.02 & $<.001$ \\
\hline Error & 6.84 & 1880 & .33 & & \\
\hline Total & 615.70 & 1884 & & & \\
\hline
\end{tabular}

First, there was a statistically significant group difference on mental toughness $\left(F_{4,1880}=10.73, p<\right.$ $\left..001, \eta^{2}=.02\right)$, and these differences followed a linear trend $\left(F_{1,1880}=38.11, p<.001, \eta^{2}=.02\right)$. As seen in Figure 1 (below), mental toughness motives decreased steadily with age. Second, there was a significant group difference in motives included in the toned and fit factor $\left(F_{4,1880}=8.70, p<.001\right.$, 
$\left.\eta^{2}=.02\right)$. Trend analyses revealed significant linear $\left(F_{1,1880}=23.79, p<.001, \eta^{2}=.01\right)$ and quadratic $\left(F_{1,1880}=10.04, p<.01, \eta^{2}=.005\right)$ trends; however the linear trend accounted for the greatest proportion of variance in the group effect. As depicted in Figure 1, there is a steady increase with age with respect to motives encompassed in toned and fit. Third, there was a statistically significant group difference on the factor of fun and friends $\left(F_{4,1880}=6.67, p<.001, \eta^{2}=.01\right)$, and these motives decreased linearly with age $\left(F_{1,1880}=24.31, p<.001, \eta^{2}=.01\right)$. Lastly, stress reduction motives differed by group $\left(F_{4,1880}=6.56, p<.001, \eta^{2}=.01\right)$ and all trends were statistically significant (see Table 3). The quadratic trend accounted for the largest proportion of variance in stress reduction motives; however, this corresponded to a relatively small effect size $(.06 \%$ of the variance).

Figure 1. Group means on motivations subscales

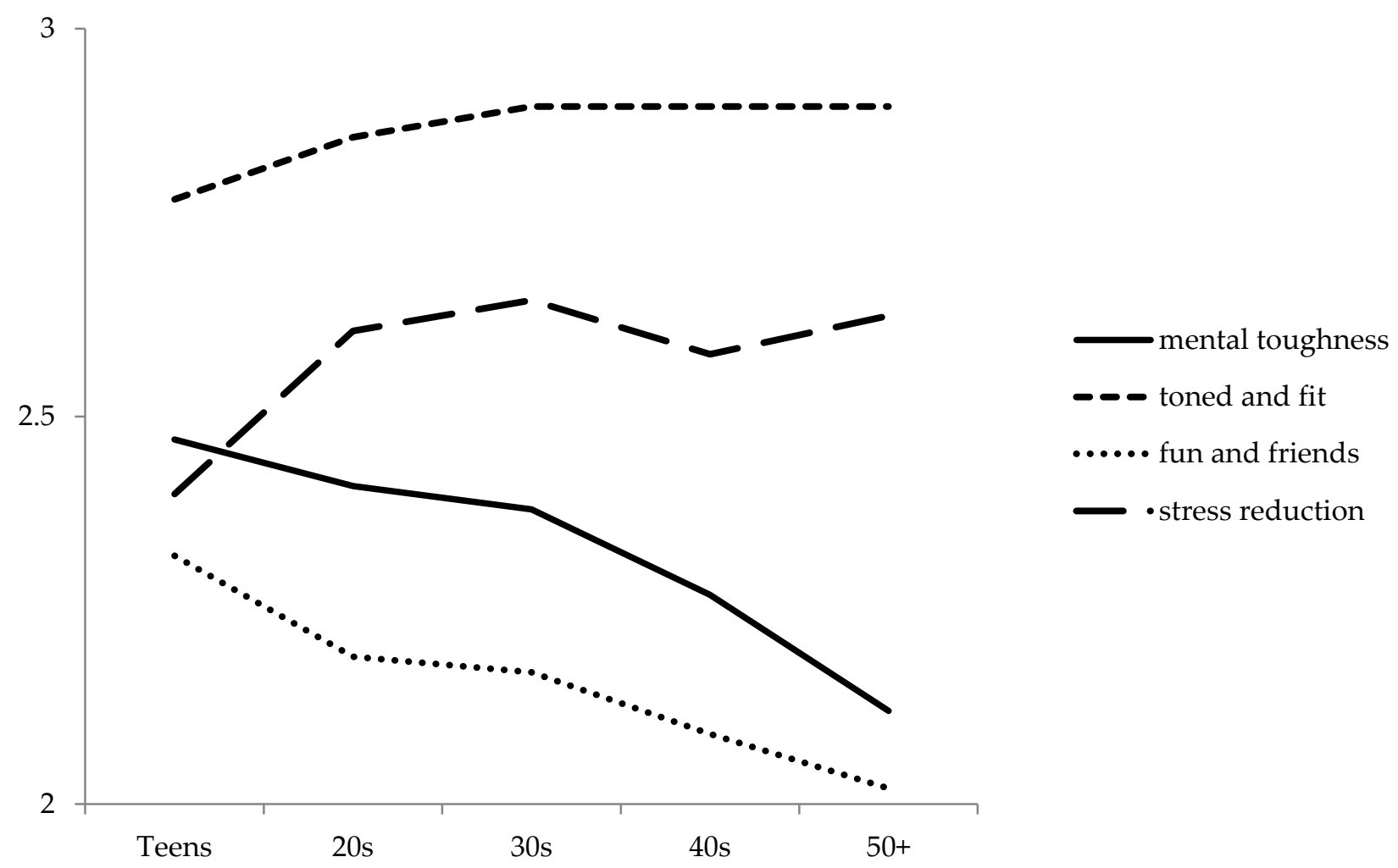

\section{Discussion}

The EFA revealed four motivational factors: mental toughness, toned and fit, fun and friends, and stress reduction. These factors seemed to have reasonable internal consistency, and suggested a simplified framework for appreciating motivations for exercise. Especially when attempting to design promotional campaigns or activity programming, having a more concise portrayal of age group differences - such as the one permitted by this four-factor solution - may facilitate understanding and planning.

A closer examination of our EFA raised an important theoretical issue deriving from the seeming mix of intrinsic and extrinsic elements in certain factors. If we consider, for example, the toned and fit (F2) factor, there were items referring to future health, being fit, improving endurance, body shaping, and increasing physical attractiveness. As Ryan et al. (2009) commented, intrinsic PA motives pertain to goals of becoming healthy and fit, while extrinsic 
motives are derived more from a desire for physical attractiveness. This argument was thought to be supported by factor analytic results reported by Kasser and Ryan (1996) wherein items pertaining to health loaded on factors with intrinsic motivational items, while items concerning physical attractiveness loaded on factors containing items related to monetary goals or fame (extrinsic rewards). In our study, the motive of increasing physical attractiveness loaded on the same factor as items pertaining to fitness and health. One way of reconciling this apparent difference in factorial structures relies on arguments taken from organismic integration theory (OIT; see Deci \& Ryan, 1985; Ryan \& Deci, 2000), a sub-theory of SDT. OIT suggests a continuum of autonomy underpinning extrinsic motivation. Motives that are more autonomous are likely to be integrated into and internalized in the self. As such, they would approximate intrinsic motives in their capacity to support sustained involvement (Ryan et al., 2009). In this perspective, our finding that intrinsic motives related to health and fitness loaded on the same factor as a seemingly extrinsic motive of physical attractiveness makes sense, especially if the latter was considered to be internalized and integrated into the self. A similar argument could be made for motives comprising the stress reduction (F4) factor, where items varied from ones concerning anxiety and mood management to those pertaining to increasing relaxation and reducing tension.

In relation to the principal focus of our investigation, namely, the comparison of exerciserelated motivations across the lifespan, the EFA results can be seen as providing a simple framework of four factors for comparison. Variance in the four motivational factors across the lifespan is captured graphically in Figure 1, and detailed in the univariate ANOVA results and related polynomial trend analyses displayed in Table 3. Assuming that the EFA-identified factors adequately map dominant categories of exercise motivation, Figure 1 largely describes two patterns: One suggests an increase in the salience of certain motives over the lifespan, while the second depicts a declining basis for exercise motivation as individuals age. The first pattern was evident for the factors of stress reduction and toned and fit, while the second seemed to characterize the motivational factors of mental toughness and fun and friends. Though quadratic trends were evident for the factors of stress reduction and toned and fit, linear trends were significant for all four of the factors; it is these linear trends that we would like to emphasize in our discussion.

Apparently, as individuals age, they express progressively less motivation to exercise based on a desire to enhance aspects of mental toughness. Connaughton, Hanton, and Jones (2010) argued in their study of elite athletes that mental toughness was indeed an important outcome that could be nurtured through sport and activity participation. However, it appears from our research that this becomes less relevant with increasing age. Bear in mind that our mental toughness factor was comprised of items that extended beyond narrower definitions of this construct (Madrigal, Hamill, \& Gill, 2013; Nicholls, Polman, Levy, \& Backhouse 2009). Exercise motives that loaded significantly on this factor reflected interest in developing assertiveness, creating opportunities for achievement, building self-esteem, generating new life skills, and becoming mentally tougher. The trend line for this composite of motivations for exercising drops off right after the teen years and continues its decline into and beyond the 50s. While research supports the notion that elements of the mental toughness factor, for instance, self-esteem and experiencing mastery, can be favorably impacted through exercise participation (Hawker, 2012; Spence, McGannon, \& Poon, 2005; Springer, Lamborn, \& Pollard, 2013), the fact that older individuals appear to be less motivated to exercise for such reasons might suggest that either these concerns are less relevant to their lives (e.g., self-esteem is reasonably well-established; see Wagner, Gerstorf, Hoppmann, \& Luszcz, 2013) or that exercising has stronger connections to other personal goals. 
Similarly, according to our findings being with friends, having fun, living adventurously, and enjoying competitive challenges become less potent motivators for exercise as one ages. The high importance of fun in PA has been noted in a single cohort study of 14-18 year olds (Pano \& Markola, 2012), but this result provides only partial insight into the meaning of fun and friends across the lifespan. Fortunately, Seippel's (2006) study of over 1,400 Norwegian recreational athletes provides greater contrast for our research. To begin, this study identified joy/fun as the most meaningful reason for exercising, while in our investigation the fun and friends factor had the lowest mean scores in all age groups. Of course, our factor consisted of items beyond just having fun. In regard to age comparisons, the Norwegian study corroborated our trends in its documentation of the declining importance of joy/fun, social relations, and competitive achievements with age. Another variable included in the Norwegian study was the importance of personal expression through sports, which similarly showed a decline with age; this variable may bear some relationship to our item of living more adventurously, which loaded on the fun and friends factor. While the relative importance of joy/fun as a motive for exercise cannot be accurately compared due to the different methodologies of the two studies, the similarities between the two studies in age declines in fun, social relations, achievements, and self-expression or living adventurously raises concern about a diminished potency of PA to excite interest among individuals as they age.

Trends in our investigation where higher interest levels corresponded with increasing age seemed to represent a more pragmatic emphasis in exercising. While motivations related to being toned and fit evidenced the highest mean scores across all age groups, the significant linear trend for this factor documents how it becomes more central as a motivator with increasing age. Perhaps we can identify in this trend a growing awareness of one's mortality and the need to counter the effects of aging. The toned and fit factor included items pertaining to the prevention of future health problems as well as a current emphasis on body shaping and overall fitness levels. Health may be more taken for granted at a younger age, whereas aging tends to bring home the fragility of our lives (Andrews, 1999; Blum-Lehmann, 2008). Baltes's (1987, 1993, 1997) lifespan model of selective optimization with compensation gives great emphasis to age-related losses in human capacities and our need to address these losses through the selection of other goals and compensatory behaviors, which could include more instrumental ways of engaging in physical activity.

Stress reduction was another motive that seemed to increase in relevance with age. The items captured by this factor referred to reducing stress, releasing tension, increasing relaxation, and addressing mood fluctuations. Evidence pertaining to these kinds of benefits of exercise has been widely documented (Edenfield \& Blumenthal, 2011; Gerber \& Pühse, 2009). Perhaps individuals learn over time the importance of 'time out' from stressful daily events and recognize how regular physical activity can provide a reliable means of stress reduction. A parallel finding might be seen in Seippel's (2006) study, where mental recreation was found to gain increasing importance with age.

In an overall perspective, our investigation offers insights into the reasons for individual involvement in PA across the lifespan, as well as affording a fresh outlook regarding the structure of exercise motivations. We noted in our discussion of the EFA results that our factors seemed to be complexly constructed with items that could be seen as a mix of intrinsic and extrinsic exercise-related motivations. For instance, it seemed noteworthy that an item reflecting the goal of increasing physical attractiveness loaded on the same factor as items concerning health and physical fitness, which have been assumed to reflect intrinsic motivation (Kasser \& Ryan, 1996; Ryan et al., 2009). Certainly, the importance of organismic integration theory (Deci \& Ryan, 1985; 
Ryan \& Deci, 2000) in describing a continuum of motivations ranging from those that are highly controlled to ones that are autonomously pursued allows us to appreciate how extrinsic motives may be closely linked to intrinsic ones. We also argued that our EFA results provided a reasonable map of exercise motives that could facilitate comprehension of differences across various types of groupings, including our own contrasts based on age.

When considering motives across the lifespan, two summary perspectives can be offered: The first can be seen in the relative scores of the factors across age groups (Figure 1), wherein we find that the more instrumental purposes of exercise to be toned and fit rank highest for all age groups while the seemingly more personal and intrinsic purposes of fun and friends rank lowest for all age groups. The second perspective, also depicted in Figure 1, pertains to the types of motives that decline with age vs. those that grow. In this regard, pragmatic or instrumental concerns seem to trump ones that might be more personally uplifting.

In reflecting on these global impressions, we saw linkages to the pioneering work of Vallerand $(2008,2012)$ and his colleagues (Vallerand, Donahue, \& Lafrenière, 2012) regarding the construct of passion. Vallerand (2012) identifies passion as "a special relationship with an activity that one loves" (p.47). Particularly in regard to what is described as harmonious passion, there seems to be a strong element of choice and openness to participation that facilitates positive experiences. Moreover, harmonious passion also incorporates a sense of deep meaning and personal identification with what one is doing. Such passionate engagements have been related to positive states of wellbeing, life satisfaction, vitality, and the relative absence of states of illbeing. In brief, Vallerand (2012) asserts that passion is highly connected to the experience of a meaningful life.

Sport and exercise participation remains at low levels in North America, and it may be too much of a stretch to aspire for passionate engagement in PA within the population at large. Yet, as Vallerand (2012) remarks, motivation matters in regard to living a meaningful life and, moreover, people engage with their worlds in order to grow. When we think of aging as a phenomenon where one becomes more instrumental about what one does and where challenge, joy, excitement, and the desire for achievement diminish in their motivational relevance with passing years, we feel deep concern. We could easily translate our results into prescriptive recommendations for marketing fitness or for program planning, but we prefer to ask a question which unfortunately our current research cannot answer: What will it take to increase passionate relationships with physical pursuits at all ages of the lifespan? Or, perhaps as a more modest goal, what needs to happen for individuals to maintain their view of the world of sports and exercise as a place where they can be nourished in mind, body and spirit?

\author{
Authors \\ James Gavin \\ Concordia University \\ james.gavin@concordia.ca \\ Matthew Keough \\ Concordia University \\ Michael Abravanel \\ Concordia University \\ Tatiana Moudrakovski \\ Concordia University
}


Madeleine Mcbrearty

Concordia University

Publishing Timeline

Received 11 November 2013

Accepted 26 January 2014

Published 5 June 2014

\section{References}

Andrews, M. (1999). The seductiveness of agelessness. Ageing \& Society, 19(3), 301-318. http://dx.doi.org/10.1017/S0144686X99007369

Ashford, B. B., Biddle, S. S., \& Goudas, M. M. (1993). Participation in community sports centres: Motives and predictors of enjoyment. Journal of Sports Sciences, 11(3), 249-256. http://dx.doi.org/10.1080/02640419308729992

Baker, J., Fraser-Thomas, J., Dionigi, R. A., \& Horton, S. (2010). Sports participation and positive development in older persons. European Review of Aging and Physical Activity, 7(1), 3-12. http://dx.doi.org/10.1007/s11556-009-0054-9

Baltes, P. (1987). Theoretical propositions of life-span developmental psychology: On the dynamics between growth and decline. Developmental Psychology, 23(5), 611-626. http://dx.doi.org/10.1037/00121649.23.5.611

Baltes, P. B. (1993). The aging mind: Potential and limits. The Gerontologist, 33(5), 580-594. http://dx.doi.org/10.1093/geront/33.5.580

Baltes, P. (1997). On the incomplete architecture of human ontogeny: Selection, optimization, and compensation as foundation of developmental theory. American Psychologist, 52(4), 366380. http://dx.doi.org/10.1037/0003-066X.52.4.366

Biddle, S. H. (2007). Exercise motivation across the life span. In D. Smith, \& M. Bar-Eli (Eds.), Essential readings in sport and exercise psychology (pp. 378-389). Champaign, IL: Human Kinetics.

Biddle, S. H., Wang, C. J., Chatzisarantis, N. D., \& Spray, C. M. (2003). Motivation for physical activity in young people: Entity and incremental beliefs about athletic ability. Journal of Sports Sciences, 21(12), 973-989. http://dx.doi.org/10.1080/02640410310001641377

Blum-Lehmann, S. (2008). [Fragility and experiencing limits as a chance for development in old age--the meaning of the particular experiences of the aging body for identification and development as focused on the very old]. Zeitschrift Für Gerontologie Und Geriatrie, 41(3), 201-207. http://dx.doi.org/10.1007/s00391-008-0548-5

Breyer, F., Costa-Font, J., \& Felder, S. (2010). Ageing, health, and health care. Oxford Review of Economic Policy, 26(4), 674-690. http://dx.doi.org/10.1093/oxrep/grq032

Brownson, R. C., Boehmer, T. K., \& Luke, D. A. (2005). Declining rates of physical activity in the United States: What are the contributors? Annual Review Of Public Health, 26, 421-443. http://dx.doi.org/10.1146/annurev.publhealth.26.021304.144437

Brunet, J., \& Sabiston, C. M. (2011). Exploring motivation for physical activity across the adult lifespan. Psychology of Sport \& Exercise, 12(2), 99-105. http://dx.doi.org/10.1016/j.psychsport.2010.09.006

Centers for Disease Control and Prevention. (2011a). Physical activity and health: The benefits of physical activity. http://www.cdc.gov/physicalactivity/everyone/health/index.html

Centers for Disease Control and Prevention. (2011b). Exercise or physical activity. http://www.cdc.gov/nchs/fastats/exercise.htm

Colley, R. C., Didier, G., Janssen, I., Craig, C. L., Clarke, J., \& Tremblay M. S. (March 2011). Physical activity of Canadian adults: Accelerometer results from the 2007 to 2009 Canadian Health Measures Survey (Catalogue no. 82-003-X -(22)1) [Health Reports].

http://www.theglobeandmail.com/incoming/article952125.ece/BINARY/Read+the+report+from+Statis tics+Canada 
Conn, V. S., Hafdahl, A. R., \& Mehr, D. R. (2011). Interventions to increase physical activity among healthy adults: Meta-analysis of outcomes. American Journal of Public Health, 101(4), 751-758. http://dx.doi.org/10.2105/AJPH.2010.194381

Connaughton, D., Hanton, S., \& Jones, G. (2010). The development and maintenance of mental toughness in the world's best performers. Sport Psychologist, 24(2), 168-193.

Deci, E. L. (1975). Intrinsic Motivation. New York, NY: Plenum. http://dx.doi.org/10.1007/978-1-4613-44469

Deci, E. L., \& Ryan, R. (1985). Intrinsic motivation and self-determination in human behavior. New York, NY: Plenum. http://dx.doi.org/10.1007/978-1-4899-2271-7

Dishman, R. K. (1987). Exercise adherence and habitual physical activity. In W. P. Morgan, \& S. N. Goldston (Eds.), Exercise and mental health (pp. 57-83). Washington, DC: Hemisphere.

Edenfield, T. M., \& Blumenthal, J. A. (2011). Exercise and stress reduction. In R. J. Contrada, \& A. Baum (Eds.), The handbook of stress science: Biology, psychology, and health (pp. 301-319). New York, NY: Springer Publishing Co.

Edmunds, J., Ntoumanis, N., \& Duda, J. (2006). A test of self-determination theory in the exercise domain. Journal of Applied Social Psychology, 36(9), 2240-2265. http://dx.doi.org/10.1111/j.00219029.2006.00102.x

Erikson, E. H. (1980). Identity and the life cycle. New York, NY: Norton.

Erikson, E. H. (1982). The life cycle completed. New York, NY: Norton.

Ford, P., Collins, D., Bailey, R., MacNamara, Á., Pearce, G., \& Toms, M. (2012). Participant development in sport and physical activity: The impact of biological maturation. European Journal of Sport Science, 12(6), 515-526. http://dx.doi.org/10.1080/17461391.2011.577241

Frederick-Recascino, C. M. (2002). Self-determination theory and participant motivation research in the sport and exercise domain. In E. L. Deci, \& R. M. Ryan (Eds.), Handbook of self-determination research (pp. 278-294). Rochester, NY: University of Rochester Press.

Gallagher, K. M., \& Updegraff, J. A. (2011). When 'fit' leads to fit, and when 'fit' leads to fat: How message framing and intrinsic vs. extrinsic exercise outcomes interact in promoting physical activity. Psychology \& Health, 26(7), 819-834. http://dx.doi.org/10.1080/08870446.2010.505983

Gavin, J. (2004). Fitness personality Rx. The Physician and Sportsmedicine, 32(12), 17-24.

Gavin, J. (2006). Activaction: The YMCA's bold, new approach to fitness through the Fitness Personality Profile. Unpublished document, Department of Applied Human Sciences, Concordia University, Montreal, QC.

Gavin, J., Mcbrearty, M., \& Harvey, W. (2010, October). Matching activities to personal style (MAPS): Developing a physical activity guidance system for high school students. Poster session presented at the Sport Canada Research Initiative Annual Conference, Ottawa, ON.

Gavin, J., Mcbrearty, M., \& Harvey, W. (2013). Involvement in physical activity: Adolescents' perceptions of outcomes. Sage Open, 3, 1-10. http://dx.doi.org/10.1177/2158244013485094

Gerber, M., \& Pühse, U. (2009). Do exercise and fitness protect against stress-induced health complaints? A review of the literature. Scandinavian Journal of Public Health, 37(8), 801-819. http://dx.doi.org/10.1177/1403494809350522

Hagger, M. S. (2012). Advances in motivation in exercise and physical activity. In R. M. Ryan (Ed.), The Oxford handbook of human motivation (pp. 479-504). New York, NY: Oxford University Press. http://dx.doi.org/10.1093/oxfordhb/9780195399820.013.0027

Hagger, M. S., \& Chatzisarantis, N. D. (2007). Intrinsic motivation and self-determination in exercise and sport. Champaign, IL: Human Kinetics.

Hawker, C. L. (2012). Physical activity and mental well-being in student nurses. Nurse Education Today, 32(3), 325-331. http://dx.doi.org/10.1016/j.nedt.2011.07.013

Hobbs, N., Godfrey, A., Lara, J., Errington, L., Meyer, T. D., Rochester, L., \& ... Sniehotta, F. F. (2013). Are behavioral interventions effective in increasing physical activity at 12 to 36 months in adults aged 55 to 70 years? A systematic review and meta-analysis. BMC Medicine, 11(1), 1-12. http://dx.doi.org/10.1186/1741-7015-11-75 
Human Resources and Skills Development Canada (2013). Indicators of well-being in Canada. http://www4.hrsdc.gc.ca/.3ndic.1t.4r@-eng.jsp?iid=8\#M_1

Ingledew, D. K., \& Markland, D. (2008). The role of motives in exercise participation. Psychology $\&$ Health, 23(7), 807-828. http://dx.doi.org/10.1080/08870440701405704

Janssen, I. (2012). Health care costs of physical inactivity in Canadian adults. Applied Physiology, Nutrition E Metabolism, 37(4), 803-806. http://dx.doi.org/10.1139/h2012-061

Kaiser, H. F. (1960). The application of electronic computers to factor analysis. Educational and Psychological Measurement, 20(1), 141-151. http://dx.doi.org/10.1177/001316446002000116

Kasser, T., \& Ryan, R. M. (1996). Further examining the American dream: Differential correlates of intrinsic and extrinsic goals. Personality And Social Psychology Bulletin, 22(3), 280-287. http://dx.doi.org/10.1177/0146167296223006

Kegan, R. (1982). The evolving self: Problem and process in human development. Cambridge, MA: Harvard University Press.

Kegan, R. (1994). In over our heads: The mental demands of modern life. Cambridge, MA: Harvard University Press.

Kline, R. B. (1998). Principles and practice of structural equation modeling (1st ed.). New York, NY: Guilford Press.

Kline, R. B. (2009). Becoming a behavioral science researcher: A guide to producing research that matters. New York, NY: Guilford Press.

Kline, R. B. (2013). Exploratory and Confirmatory Factor Analysis. In Y. Petscher, \& C. Schatsschneider (Eds.), Applied quantitative analysis in the social sciences (pp. 171-207). New York, NY: Routledge.

Koslow, R. E. (1988). Age-related reasons for expressed interest in exercise and weight control. Journal of Applied Social Psychology, 18(4), 349-354. http://dx.doi.org/10.1111/j.1559-1816.1988.tb00021.x

Levinson, D. J. (1978). Seasons of a man's life. New York, NY: Random House.

Levinson, D. J. (1996). Seasons of a woman's life. New York, NY: Alfred A. Knopf.

Lim, W. M., Ting, D. H., Loh, K. Y., Loo, W. T., \& Shaikh, S. (2013). Men's motivation to go to the gymnasium: A study of intrinsic and extrinsic motivation. International Journal of Sport Management $\mathcal{E}$ Marketing, 13(1), 122-139.

Madrigal, L., Hamill, S., \& Gill, D. L. (2013). Mind over matter: The development of the mental toughness scale (MTS). Sport Psychologist, 27(1), 62-77.

Martín-Albo, J., Núñez, J. L., Domínguez, E., León, J., \& Tomás, J. M. (2012). Relationships between intrinsic motivation, physical self-concept and satisfaction with life: A longitudinal study. Journal of Sports Sciences, 30(4), 337-347. http://dx.doi.org/10.1080/02640414.2011.649776

McAuley, E., Wraith, S., \& Duncan, T. E. (1991). Self efficacy, perceptions of success, and intrinsic motivation for exercise. Journal of Applied Social Psychology, 21(2), 139-155. http://dx.doi.org/10.1111/j.1559-1816.1991.tb00493.x

Meyers, L. S., Gamst, G., \& Guarino, A. J. (2013). Applied multivariate research: Design and interpretation (2nd ed.). Thousand Oaks, CA: Sage.

Miller, A. M., \& Iris, M. M. (2002). Health promotion attitudes and strategies in older adults. Health Education \& Behavior, 29(2), 249-267.

Morgan, P. P., Shephard, R. J., \& Finucane, R. (1984). Health beliefs and exercise habits in an employee fitness program. Canadian Journal of Applied Sport Science, 9(2), 87-93. PMid:6733838

Mullan, E., \& Markland, D. (1997). Variations in self-determination across the stages of change for exercise in adults. Motivation and Emotion, 21(4), 349-362. http://dx.doi.org/10.1023/A:1024436423492

Muthen, L. K., \& Muthen, B. (2002). Mplus: The comprehensive modeling program for applied researchers. Los Angeles, CA: Muthen and Muthen.

Netz, Y., \& Raviv, S. (2004). Age differences in motivational orientation toward physical activity: An application of social-cognitive theory. Journal of Psychology: Interdisciplinary and Applied, 138(1), 35-48. http://dx.doi.org/10.3200/JRLP.138.1.35-48

Nicholls, A. R., Polman, R. C. J., Levy, A. R., \& Backhouse, S. H. (2009). Mental toughness in sport: Achievement level, gender, age, experience, and sport type differences. Personality \& Individual Differences, 47(1), 73-75. http://dx.doi.org/10.1016/j.paid.2009.02.006 
O'Connor, R. M., Colder, C. R., \& Hawk, L. W. (2004). Confirmatory factor analysis of the Sensitivity to Punishment and Sensitivity to Reward Questionnaire. Personality and Individual Differences, 37(5), 985-1002. http://dx.doi.org/10.1016/j.paid.2003.11.008

Pano, G., \& Markola, L. (2012). 14-18 years old children attitudes, perception and motivation towards extra curricular physical activity and sport. Journal of Human Sport \& Exercise, 7(1), S51-S66. http://dx.doi.org/10.4100/jhse.2012.7.Proc1.07

Prohaska, T. R., Leventhal, E. A., Leventhal, H., \& Keller, M. L. (1985). Health practices and illness cognition in young, middle aged, and elderly adults. Journal of Gerontology, 40(5), 569-578. http://dx.doi.org/10.1093/geronj/40.5.569

Rangul, V., Bauman, A., Lingaas Holmen, T., \& Midthjell, K. (2012). Is physical activity maintenance from adolescence to young adulthood associated with reduced CVD risk factors, improved mental health and satisfaction with life: The HUNT study, Norway. International Journal of Behavioral Nutrition \& Physical Activity, 9(1), 144-154. http://dx.doi.org/10.1186/1479-5868-9-144

Ransford, H. E., \& Palisi, B. J. (1996). Aerobic exercise, subjective health, and psychological well-being within age and gender subgroups. Social Science and Medicine, 42(11), 1555-1559. http://dx.doi.org/10.1016/0277-9536(95)00252-9

Ryan, R. M., \& Deci, E. L. (2000). Self-determination theory and the facilitation of intrinsic motivation, social development, and well-being. American Psychologist, 55(1), 68-78. http://dx.doi.org/10.1037/0003-066X.55.1.68

Ryan, R. M., Koestner, R., \& Deci, E. L. (1991). Ego-involved persistence: When free-choice behavior is not intrinsically motivated. Motivation and Emotion, 15(3), 185-205. http://dx.doi.org/10.1007/BF00995170

Ryan, R. M., Williams, G. C., Patrick, H., \& Deci, E. L. (2009). Self-determination theory and physical activity: The dynamics of motivation in development and wellness. Hellenic Journal of Psychology, $6(2), 107-124$.

Schieffer, T., \& Thomas, K. (2012). Fifteen years of promise in school-based physical activity interventions: A meta-analysis. Kinesiology Review, 1(3), 155-169.

Seippel, Ø. (2006). The meanings of sport: Fun, health, beauty or community? Sport in Society, 9(1), 51-70. http://dx.doi.org/10.1080/17430430500355790

Spence, J. C., McGannon, K. R., \& Poon, P. (2005). The effect of exercise on global self-esteem: A quantitative review. Journal of Sport \& Exercise Psychology, 27(3), 311-334

Springer, J. B., Lamborn, S. D., \& Pollard, D. M. (2013). Maintaining physical activity over time: The importance of basic psychological need satisfaction in developing the physically active self. American Journal of Health Promotion, 27(5), 284-293. http://dx.doi.org/10.4278/ajhp.110211-QUAL-62

Tabachnick, B. G., \& Fidell, L. S. (2013). Using multivariate statistics (6 ${ }^{\text {th }}$ ed.). Boston, MA: Allyn and Bacon.

Teixeira, P. J., Carraça, E. V., Markland, D., Silva, M. N., \& Ryan, R. M. (2012). Exercise, physical activity, and self-determination theory: A systematic review. The International Journal of Behavioral Nutrition and Physical Activity, 9. http://dx.doi.org/10.1186/1479-5868-9-78

Trujillo, K. M., Brougham, R. R., \& Walsh, D. A. (2004). Age differences in reasons for exercising. Current Psychology, 22(4), 348-367. http://dx.doi.org/10.1007/s12144-004-1040-z

U.S. Department of Health and Human Services. (2008). Physical activity guidelines advisory committee report. Physical Activity Guidelines Advisory Committee. Washington, DC. http://www.health.gov/paguidelines/Report/pdf/CommitteeReport.pdf

Vallerand, R. J. (2008). On the psychology of passion: In search of what makes people's lives most worth living. Canadian Psychology, 49(1), 1-13.

Vallerand, R. J. (2012). From motivation to passion: In search of the motivational processes involved in a meaningful life. Canadian Psychology, 53(1), 42-52. http://dx.doi.org/10.1037/a0026377

Vallerand, R. J., Donahue, E. G., \& Lafrenière, M. K. (2012). Intrinsic and extrinsic motivation in sport and exercise. In G. Tenenbaum, R. C. Eklund, \& A. Kamata (Eds.), Measurement in sport and exercise psychology (pp. 279-292). Champaign, IL: Human Kinetics. 
Wagner, J., Gerstorf, D., Hoppmann, C., \& Luszcz, M. A. (2013). The nature and correlates of self-esteem trajectories in late life. Journal of Personality \& Social Psychology, 105(1), 139-153.

http://dx.doi.org/10.1037/a0032279

Wankel, L. M. (1985). Personal and situational factors affecting exercise involvement: The importance of enjoyment. Research Quarterly for Exercise and Sport, 56(3), 275-282. http://dx.doi.org/10.1080/02701367.1985.10605374

Wankel, L. M. (1988). Exercise adherence and leisure activity. Patterns of involvement and interventions to facilitate regular activity. In R. K. Dishman (Ed.), Exercise adherence: Its impact on public health (pp. 369-396). Champagne, IL: Human Kinetics.

Wankel, L. M. (1993). The importance of enjoyment to adherence and psychological benefits from physical activity. International Journal of Sport Psychology, 24(2), 151-169.

Wilkinson, L., \& the Task Force on Statistical Inference. (1999). Statistical methods in psychology journals: Guidelines and explanations. American Psychologist, 54(8), 594-604.

http://dx.doi.org/10.1037/0003-066X.54.8.594 